\title{
Optimized combinations of abatement strategies for urban mobile sources
}

\author{
Tai-Yi Yu *, Yu-Chyang Lin, Len-Fu W. Chang \\ Graduate Institute of Environmental Engineering, National Taiwan University, Taiwan 71, Chou-Shan Road, Taipei, Taiwan
}

Received 7 June 1999; accepted 2 August 1999

\begin{abstract}
The maximum incremental reactivity (MIR) scale was chosen as a practical index for quantifying ozone-forming impacts. The integer linear and nonlinear programming techniques were employed as the optimization method to maximize MIR and volatile organic compound (VOC) reductions, and minimize ozone's marginal cost with varied control costs. Mobile vehicles were divided into nine categories according to the demands of decision makers and the distinctive features of local circumstance in metro-Taipei. The emission factor (EF) and vehicle kilometers traveled (VKT) of each kind of vehicle were estimated by MOBILE5B model via native parameters and questionnaires. Compressed natural gas $(\mathrm{CNG})$ and inspection and maintenance $(\mathrm{I} / \mathrm{M})$ were the alternative control programs for buses and touring buses; liquefied petroleum gas (LPG), I/M, methanol, electrical vehicle (EV) were for taxis and low duty gasoline vehicles. EV, methanol, and I/M were the possible control methods for two-stroke and four-stroke engine motorcycles; I/M programs for low-duty diesel trucks, heavy-duty diesel trucks, and low-duty gasoline trucks.

The results include the emission ratios of specific vehicle to all vehicles, the best combination of abated measures based on different objectives, and the marginal cost for ozone and VOC with varied control costs. (c) 2000 Elsevier Science Ltd. All rights reserved.
\end{abstract}

Keywords: MIR; Abatement strategies; Mobile source; Optimization, Marginal cost;

\section{Introduction}

The intensifying ozone problems in urban areas have made it imperative that researchers better understand the emission reduction of the ozone precursors, nitrogen oxides $\left(\mathrm{NO}_{x}\right)$ and volatile organic compound (VOC). Vehicle exhaust is the major source of $\mathrm{NO}_{x}$ and VOC in the atmosphere. Alternatively fueled vehicles have the potential to improve air quality, even though the number of vehicles is expected to increase in the future. Traditional control programs for mobile sources in ur-

\footnotetext{
* Corresponding author. Tel.: +886-2-8787-9037; fax: +8862-2362-6243.

E-mail address: d2507005@ms31.hinet.net (T.-Y. Yu).
}

ban areas have focused on the mass reduction of VOC. Conventional fueled vehicles are highly reactive in the atmosphere because they are rich in aromatics and alkenes (National Research Council, 1991). Individual VOC can differ significantly in their contributions of ozone and the maximum incremental reactivity (MIR) scale is a useful index for quantifying ozone-forming impacts. The emission rates for each alternative fuel were multiplied by the reactivity adjustment factors (RAF) for both MIR and the maximum ozone incremental reactivity (MOIR) scales (Russell et al., 1995; California Air Resources Board, 1991). Some researchers (Mcnair et al., 1994) have demonstrated that the MIR scale would be more applicable to urban core conditions, where VOC control is most effective than to rural areas. Moreover, Chang and Rudy (1990) found 
that simplified incremental reactivity methods are useful for evaluating the ozone-forming potentials of emissions from various alternative fuels.

Recently, when pollutant standards index (PSI) values have exceeded 100 in Taiwan, the probability of priority ozone has been increased while suspended particulate has declined (Chang, 1997). The probability of priority ozone surpassed that of the suspended particulate for the first time in 1997. Emissions from on-road vehicles (Lucher et al., 1992) were $56 \%$ of the total national emissions of $\mathrm{NO}_{x}, 32 \%$ of VOC and $82 \%$ of carbon monoxide $(\mathrm{CO})$. Since the emission ratios from mobile sources were even greater in urban area, significant reductions in motor vehicles would be necessary to meet National Ambient Air Quality Standard (NAAQS) in urban areas.

Examining the best combinations of abated measures for mobile sources remains a problematic when an MIR scale is used as the evaluation index. We have three aims in this paper. First of all, the emission weights of specific vehicles for both the VOC and MIR based systems must be verified. Secondly, the best combinations of alternative programs for urban mobile sources are examined across the varied control costs using both the MIR scale and an optimization tool. The minimum value of ozone's marginal cost is taken as an indicator to affirm the best solution, since it is the most economical. Thus, the optimized combinations of different objectives, the maximum MIR and VOC reductions, and the minimum ozone's marginal cost are compared and analyzed. Finally, the performance of the abated strategies across varied control costs and marginal cost for MIR and VOC are prioritized in order of their results.

\section{Methods}

The classification of vehicles is also important because it can affect the decision quality of abatement strategies for mobile vehicles. Taiwanese vehicles are traditionally divided into a large, small and motorcycle category in calculating vehicles' activities. Vehicle types provided in MOBILE5B model (USEPA, 1996) are different from those that exist in Taiwan. In order to match the demands of decision makers, mobile vehicles are divided into nine categories: buses, touring buses, heavy-duty diesel trucks (HDDT), low-duty gasoline vehicles (LDGV), taxis, low-duty gasoline trucks (LDGT), low-duty diesel trucks (LDDT), twostoke engine motorcycles (MC2), and four-stoke engine motorcycles (MC4). Emissions from motor vehicles are calculated by multiplying EF by the vehicle kilometers traveled (VKT), that form is shown as the following:

$$
\mathrm{ET}=\sum \sum\left(\mathrm{EF}_{m, v} \times \mathrm{VKT}_{v}\right)
$$

where ET is the total emission for one year, in $\mathrm{g} / \mathrm{yr}$; $\mathrm{EF}_{m, v}$ the estimated emission factor from model year, $m$ of vehicle class, $v$ in $\mathrm{g} / \mathrm{km} ; \mathrm{VKT}_{v}$ is the total vehicle kilometers traveled per year by vehicle class, $v$ in $\mathrm{km}$.

There are two basic ways to reduce emissions: degrade the EF or decrease the VKT. EF abated methods are the most practical for Taiwan. We estimated the EF for every vehicle according to the MOBILE5B model with local parameters such as vehicle age, annual mileage accumulation for 25 years, average traveling speed, as well as the VKT mix, basic emission rate, deterioration rate. Taiwan Environmental Protection Agency (TEPA, 1996) established the native driving pattern as the Taipei Automobile Driving Cycle (TADC) for automobiles and the Taipei Motorcycle Driving Cycle (TMDC) for motorcycles by sampling 15 automobiles and 45 motorcycles from metro-Taipei. The native driving patterns were utilized to correct the standard $\mathrm{CO}, \mathrm{NO}_{x}$ and VOC emission factors estimated from MOBILE5B model.

The VKT for buses, HDDV and touring buses were estimated by examining questionnaires from maintenance factories. Moreover, the VKT for other six vehicles were assessed by questionnaires from 23 gas stations around metro-Taipei. The compositions of gasoline and diesel fuels were estimated via the SPECIATE (USEPA, 1993) model, while the MIR values of the VOC were decided by the simulation (Carter, 1994). The average VKT and EF of each vehicle are shown in Table 1. The MIR is defined for the $\mathrm{VOC} / \mathrm{NO}_{x}$ ratio that leads to the maximum sensitivity to VOC.

$\mathrm{MIR}_{i}=\max \left(\frac{\partial\left[\mathrm{O}_{3}\right]_{\mathrm{p}}}{\partial E_{i}}\right)$ for all $\mathrm{VOC} / \mathrm{NO}_{x}$,

where $\left[\mathrm{O}_{3}\right]_{\mathrm{p}}$ is the peak ozone concentrations; $E_{i}$ is the emission of $i$ th VOC.

Various alternative fuels programs have been undertaken in Brazil, Canada, New Zealand, South Korea, and the Netherlands among other countries. Twenty abatement strategies, which utilize local related cost and effectiveness information, were considered as feasible control strategies. $\mathrm{CNG}$ and $\mathrm{I} / \mathrm{M}$ are the alternative control procedures for buses and touring buses; LPG, I/M, M85 (mixture of 15\% gasoline and $85 \%$ methanol) and EV for LDGV. LPG, I/M, M85 were usable methods for taxis; EV, M85 and I/M for two-stroke and fourstroke engine motorcycles; while I/M programs are used for HDDV, LDDT and LDGT. The effectiveness of I/M policies for nine vehicles and the 20 control strategies are listed in Tables 1 and 2, respectively.

The branch-and-bound algorithm of integer linear programming (Haith, 1982) can address the maximum VOC and MIR reductions in light of the discontinuous variables. This formula can be depicted as the following: 
Table 1

The VKT and EF values for each vehicle

\begin{tabular}{|c|c|c|c|c|c|c|c|c|c|}
\hline \multirow[t]{2}{*}{ Type } & \multirow[t]{2}{*}{ Numbers $^{\mathrm{a}}$} & \multirow[t]{2}{*}{ Samples } & \multirow[t]{2}{*}{ Minimum $^{\mathrm{b}}$} & \multirow{2}{*}{$\begin{array}{l}\text { VKT } \\
(\mathrm{km} / \mathrm{yr})\end{array}$} & \multirow{2}{*}{$\begin{array}{l}\mathrm{EF}^{\mathrm{c}}(\mathrm{VOC}) \\
(\mathrm{g} / \mathrm{km})\end{array}$} & \multirow{2}{*}{$\begin{array}{l}\text { MIR }^{\mathrm{d}} \\
(\mathrm{g} \mathrm{o} / \mathrm{g}) \text { voc }\end{array}$} & \multirow{2}{*}{$\begin{array}{l}\mathrm{I} / \mathrm{M}^{\mathrm{e}} \\
(\%)\end{array}$} & \multicolumn{2}{|l|}{$\mathrm{ET}^{\mathrm{f}}$} \\
\hline & & & & & & & & $\operatorname{VOC}(\%)$ & $\operatorname{MIR}(\%)$ \\
\hline Bus $^{g}$ & 4993 & 4934 & - & 62276 & 13.59 & 0.982 & 2.00 & 1.18 & 0.67 \\
\hline $\mathrm{HDDT}^{\mathrm{g}}$ & 43651 & - & - & 556769 & 13.02 & 0.982 & 2.00 & 8.83 & 5.01 \\
\hline $\begin{array}{l}\text { Touring } \\
\text { bus }^{\mathrm{g}}\end{array}$ & 5643 & - & - & 63289 & 13.59 & 0.982 & 2.00 & 1.35 & 0.77 \\
\hline $\mathrm{LDGV}^{\mathrm{h}}$ & 1364577 & 524 & 355 & 17891 & 4.74 & 1.860 & 6.00 & 32.28 & 34.71 \\
\hline Taxi $^{h}$ & 70870 & 208 & 206 & 54700 & 5.36 & 1.860 & 6.00 & 5.80 & 6.23 \\
\hline $\mathrm{LDGT}^{\mathrm{h}}$ & 137992 & $314^{\mathrm{i}}$ & $288^{\mathrm{i}}$ & 20050 & 3.98 & 1.860 & 6.00 & 3.07 & 3.30 \\
\hline $\mathrm{LDDT}^{\mathrm{h}}$ & 47582 & & & 20050 & 13.02 & 0.982 & 2.00 & 3.46 & 1.97 \\
\hline $\mathrm{MC} 2^{\mathrm{h}}$ & 1909482 & $529^{j}$ & $318^{j}$ & 6214 & 9.92 & 1.860 & 11.50 & 32.83 & 35.30 \\
\hline $\mathrm{MC}^{\mathrm{h}}$ & 1075783 & & & 8462 & 4.41 & 1.860 & 5.62 & 11.20 & 12.04 \\
\hline
\end{tabular}

${ }^{\text {a }}$ Registered numbers in metro-Taipei until 1996.

${ }^{\mathrm{b}}$ Minimum necessary numbers based on Kuo test (Kuo, 1988).

${ }^{\mathrm{c}}$ Source: TEPA, 1997; USEPA, 1996.

${ }^{\mathrm{d}}$ Source: USEPA, 1993.

${ }^{\mathrm{e}}$ VOC reduction rate of I/M measure for various motors, source: TEPA, 1997.

${ }^{\mathrm{f}}$ The emission percentage of single motor to overall motors.

${ }^{\mathrm{g}}$ Sampling in the bus or truck maintenance factories.

${ }^{\mathrm{h}}$ Sampling in 23 gas stations.

${ }^{\mathrm{i}}$ Including LDGT and LDDT.

${ }^{\mathrm{j}}$ Including MC2 and MC4.

$$
\begin{array}{cl}
\text { Maximize } & \sum X_{i, j} A_{i, j} \\
\text { subject to } & C_{i, j} X_{i, j} \leqslant \mathrm{TC} \\
& G_{k} X_{i, j} \leqslant,=, \text { or } \geqslant B_{k},
\end{array}
$$

where $X_{i, j}$ is the reduction percentage of total vehicle numbers for $i$ motor, $j$ strategy; $A_{i j}$ is the reduction effectiveness of ozone or VOC for reducing $0.1 \%$ of total vehicle numbers for $i$ motors, $j$ strategy; in $\mathrm{kg} \mathrm{o} 3 / \mathrm{yr}$ or $\mathrm{kg}$ $\mathrm{VOC} / \mathrm{yr} ; C_{i, j}$ is the cost of VOC for reducing $0.1 \%$ of total vehicle numbers for $i$ motor, $j$ strategy; $G_{k}$ is the $k$ th constraint; $B_{k}$ is the $k$ th right side.

A LINGO nonlinear solver, which employs both successive linear programming (SLP) and generalized reduced gradient (GRG) algorithms, is employed to find the minimum ozone's marginal cost. The following equation represents a model of the minimum ozone's marginal cost:

$$
\begin{array}{ll}
\text { Minimize } & \sum X_{i, j} M_{i, j} / \sum C_{i, j} X_{i, j} \\
\text { subject to } & \sum D_{i, j} X_{i, j} \leqslant E \\
& G_{k} X_{i j} \leqslant,=, \text { or } \geqslant B_{k},
\end{array}
$$

where $M_{i, j}$ is the reduction effectiveness of ozone for reducing $0.1 \%$ of $i$ motors, $j$ strategy; in $\mathrm{kg} \mathrm{o} 3 / \mathrm{yr} ; D_{I, j}$ is the reduction effectiveness of VOC for reducing $0.1 \%$ of $i$ motors, $j$ strategy; in $\mathrm{kg} \mathrm{VOC/yr;} E$ is the VOC reductions with $2 \%$ error; $B_{k}$ is a limited factor affected by the alternative fuels, control costs, control devices and other resources. $0.1 \%$ is adopted as one integer unit to fit the demands of integer programming. The constraints of the optimization program are as following:

1. The maximum percentage of performing I/M programs for HDDT, buses, touring buses, LDGV, taxis, LDGT, LDDT, MC2 and MC4 was $100 \%$, $100 \%, 100 \%, 20 \%, 100 \%, 20 \%, 20 \%, 30 \%$ and $30 \%$, respectively.

2. The maximum number of vehicles was 10000 for CNG buses and touring buses; 100000 for LPG; 100000 for methanol motors and methanol motorcycles; 40000 for electrical motorcycles.

3. The percentage of performing I/M program for MC2 and $\mathrm{MC} 4$ was the same.

\section{Discussion}

Table 1 lists registered vehicle numbers, EF, VKT of nine vehicles. The registered numbers of MC2 and MC4 were 1.40 and 0.79 times that of LDGV in Metro-Taipei. The VKT of buses, touring buses, HDDT and taxis were about 3.48, 3.11, 3.54 and 3.06 times that of LDGV. The VKT of motorcycles in the MC2 and MC4 groups were 0.347 and 0.473 times that of LDGV. Vehicles in the MC2, LDGV and MC4 groups have the highest VOC and MIR emission ratios with weights about 33-35\%, $32-34 \%$ and $11-12 \%$ to the total emission of mobile source.

The following assumptions can be made from the native costs and effectiveness for 20 abatement alternatives as listed in Table 2: 
Table 2

The costs and effectiveness of numerous abatement strategies ${ }^{\mathrm{a}}$

\begin{tabular}{|c|c|c|c|c|c|c|c|c|}
\hline \multirow[t]{2}{*}{ Type $^{b}$} & \multirow{2}{*}{$\begin{array}{l}\text { Subsidiary }^{\mathrm{c}} \\
\text { NTD } \\
\text { (yr/vehicle) }\end{array}$} & \multirow{2}{*}{$\begin{array}{l}\text { Fuel }^{\mathrm{d}} \\
\text { NTD } \\
\text { (yr/vehicle) }\end{array}$} & \multirow{2}{*}{$\begin{array}{l}\text { Operation }^{\text {e }} \\
\text { NTD } \\
\text { (yr/vehicle) }\end{array}$} & \multirow{2}{*}{$\begin{array}{l}\text { Total cost } \\
\text { NTD } \\
\text { (yr/vehicle) }\end{array}$} & \multicolumn{2}{|c|}{ Abatement effectiveness } & \multicolumn{2}{|l|}{ Average cost } \\
\hline & & & & & $\begin{array}{l}\text { Ozone } \\
(\mathrm{g} \mathrm{o} / \mathrm{km})\end{array}$ & $\begin{array}{l}\text { VOC } g \\
\text { VOC }(\mathrm{km})\end{array}$ & $\begin{array}{l}\text { Ozone NTD } \\
(\mathrm{kg} / \mathrm{yr})\end{array}$ & $\begin{array}{l}\text { VOC NTD } \\
(\mathrm{kg} / \mathrm{yr})\end{array}$ \\
\hline $\mathrm{X} 11$ & 500000 & -93414 & 81000 & 487586 & 12.013 & 12.230 & 652 & 640 \\
\hline $\mathrm{X} 12$ & 665 & 0 & 0 & 665 & 0.072 & 0.073 & 149 & 146 \\
\hline $\mathrm{X} 21$ & 665 & 0 & 0 & 665 & 3.437 & 3.500 & 174 & 171 \\
\hline $\mathrm{X} 31$ & 500000 & -94934 & 81000 & 486066 & 12.013 & 12.230 & 639 & 628 \\
\hline $\mathrm{X} 32$ & 665 & 0 & 0 & 665 & 0.072 & 0.073 & 147 & 144 \\
\hline $\mathrm{X} 41$ & 0 & -6977 & 17350 & 10373 & 5.994 & 1.860 & 97 & 312 \\
\hline $\mathrm{X} 42$ & 665 & 0 & 0 & 665 & 0.142 & 0.076 & 262 & 488 \\
\hline $\mathrm{X} 43$ & 0 & 0 & 68000 & 68000 & 7.827 & 2.230 & 486 & 1704 \\
\hline $\mathrm{X} 44$ & 0 & 0 & 200000 & 200000 & 8.444 & 4.540 & 1324 & 2462 \\
\hline X51 & 25000 & -21333 & 17350 & 21017 & 6.775 & 2.100 & 57 & 183 \\
\hline $\mathrm{X} 52$ & 665 & 0 & 0 & 665 & 0.161 & 0.086 & 76 & 141 \\
\hline X53 & 0 & 0 & 68000 & 68000 & 8.851 & 2.520 & 140 & 493 \\
\hline X61 & 665 & 0 & 0 & 665 & 0.119 & 0.064 & 278 & 517 \\
\hline X71 & 665 & 0 & 0 & 665 & 0.072 & 0.073 & 463 & 454 \\
\hline $\mathrm{X} 81$ & 117 & 0 & 0 & 117 & 0.780 & 0.419 & 24 & 45 \\
\hline $\mathrm{X} 82$ & 0 & 0 & 5500 & 5500 & 16.383 & 4.670 & 54 & 190 \\
\hline $\mathrm{X} 83$ & 5000 & 7084 & 0 & 12084 & 18.079 & 9.720 & 108 & 200 \\
\hline X91 & 117 & 0 & 0 & 117 & 0.174 & 0.093 & 80 & 148 \\
\hline X92 & 0 & 0 & 5500 & 5500 & 7.411 & 2.400 & 88 & 271 \\
\hline X93 & 5000 & 9447 & 0 & 14447 & 7.831 & 4.210 & 218 & 406 \\
\hline
\end{tabular}

${ }^{\text {a }}$ Positive values means cost more money than the original vehicle, and negative value presents the savings, the conversion rate of USD to NTD is about 23.8 to 1 .

${ }^{\mathrm{b}} \mathrm{X} 11$ : CNG for bus, X12: I/M for bus, X21: I/M for HDDT, X31: CNG for touring bus, X32: I/M for touring bus, X41: LPG for LDGV, X42: I/M for LDGV, X43: M85 (85\% methanol and 15\% gasoline) for LDGV, X44: EV for LDGV, X51: LPG for taxi, X52: I/ M for taxi, X53: M85 for taxi, X61: I/M for LDGT, X71: I/M for LDDT, X81: I/M for MC2, X82: M85 for MC2, X83: EV for MC2, X91:I/M for MC4, X82: M85 for MC4, X83:EV for MC4.

${ }^{\mathrm{c}}$ By the government.

${ }^{\mathrm{d}}$ The difference between alternative fuel and original fuel.

${ }^{\mathrm{e}}$ Including the tampering and operation costs.

1. The first five measures with the lowest ozone's average costs were I/M for MC2 (24 NT/kg/yr), M85 for MC2 (54 NT/kg/yr), LPG for taxis (57 NT/kg/yr), I/M for taixs $(76 \mathrm{NT} / \mathrm{kg} / \mathrm{yr})$ and $\mathrm{I} / \mathrm{M}$ for MC4 $(80 \mathrm{NT} / \mathrm{kg} / \mathrm{yr})$. The first five measures with the lowest VOC's average costs were I/M for MC2 (45 NT/kg/yr), I/M for taxis (141 NT/kg/yr), I/M for touring buses (144 NT/kg/yr), $\mathrm{I} / \mathrm{M}$ for buses $(144 \mathrm{NT} / \mathrm{kg} / \mathrm{yr})$ and I/M for MC4 (148 $\mathrm{NT} / \mathrm{kg} / \mathrm{yr}$ ).

2. MC2 and taxi were the first two vehicle types to match abatement programs according to the lowest average costs of ozone and VOC.

3. I/M for MC2 vehicles was the best policy that possessed both the lowest average cost for ozone and VOC.

4. The average cost of M85 motorcycles was lower than that of electrical motorcycles.

5. Using electricity for low duty vehicle was the most expensive control measure in terms of both the ozone and VOC average cost.

6. MC2 vehicles were in greater need of control measures than MC4 vehicles because the former emitted more VOC than the later group.
Substituting MC2 with electrical motorcycles would reduce ozone more than substituting them with MC4 vehicles.

Tables 3-5 list the most feasible combinations of control strategies in terms of the maximum MIR and VOC emission reductions, and the minimum ozone's marginal cost. These tables reveal the following:

1. The most feasible strategy of the control programs for the three different objectives was I/M policy for motorcycles.

2. MC2 was the first vehicle type to proceed with abatement strategies, taxis were the second choice.

3. The affect of I/M policies in decreasing order: motorcycles, taxis, HDDT, buses, touring bus, LDGV, LDGT and LDDT.

4. There were several differences among three objectives while the control costs were lower than 2.8 billion NTD per year. M85 motorcycles and LPG taxies have higher proceeding priorities than $\mathrm{I} / \mathrm{M}$ policies for HDDT, buses, touring buses and taxis in the MIR based system. The VOC system, however, reached a contrary condition. M85 motorcycles and LPG taxis have a higher proceeding priorities than 


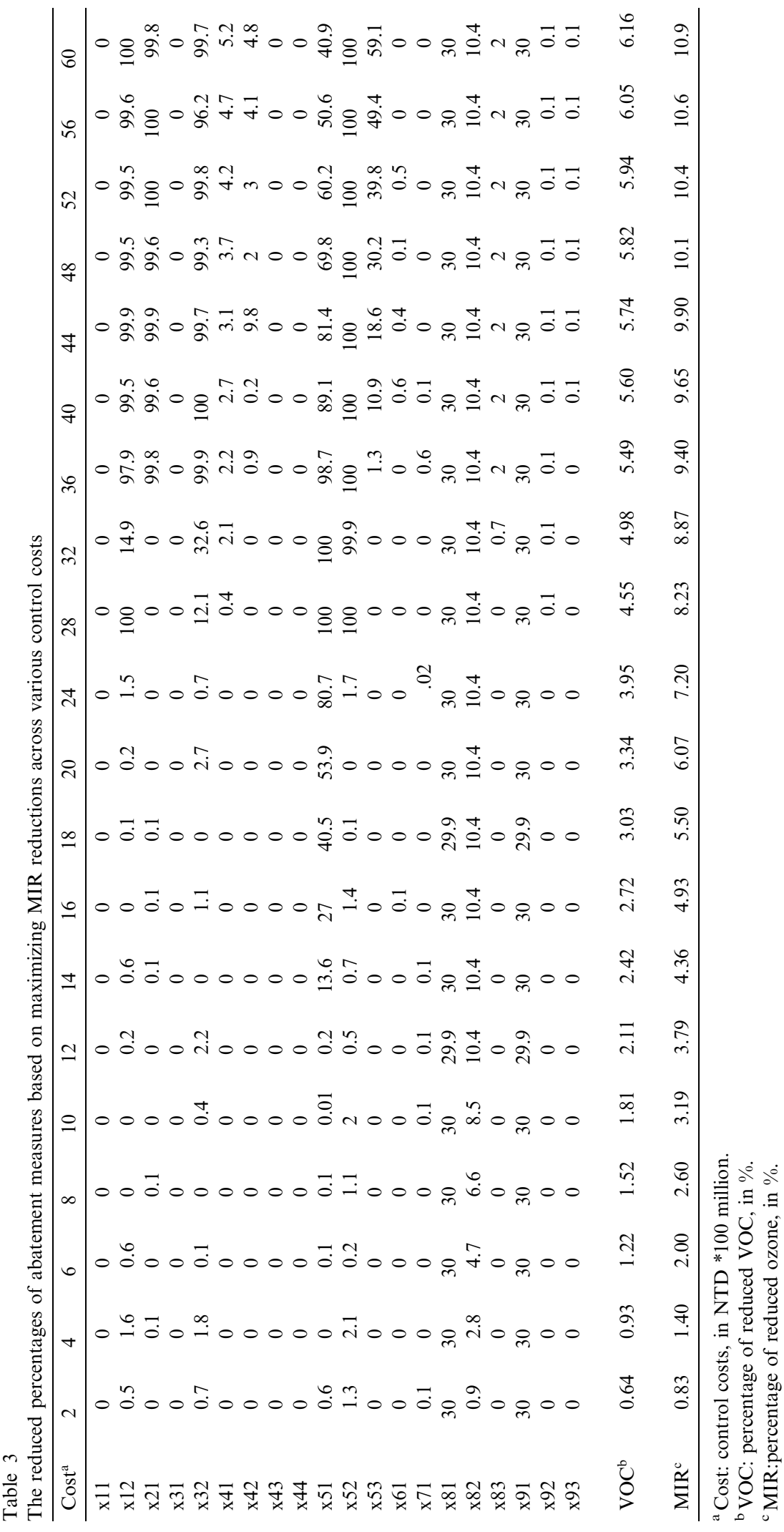




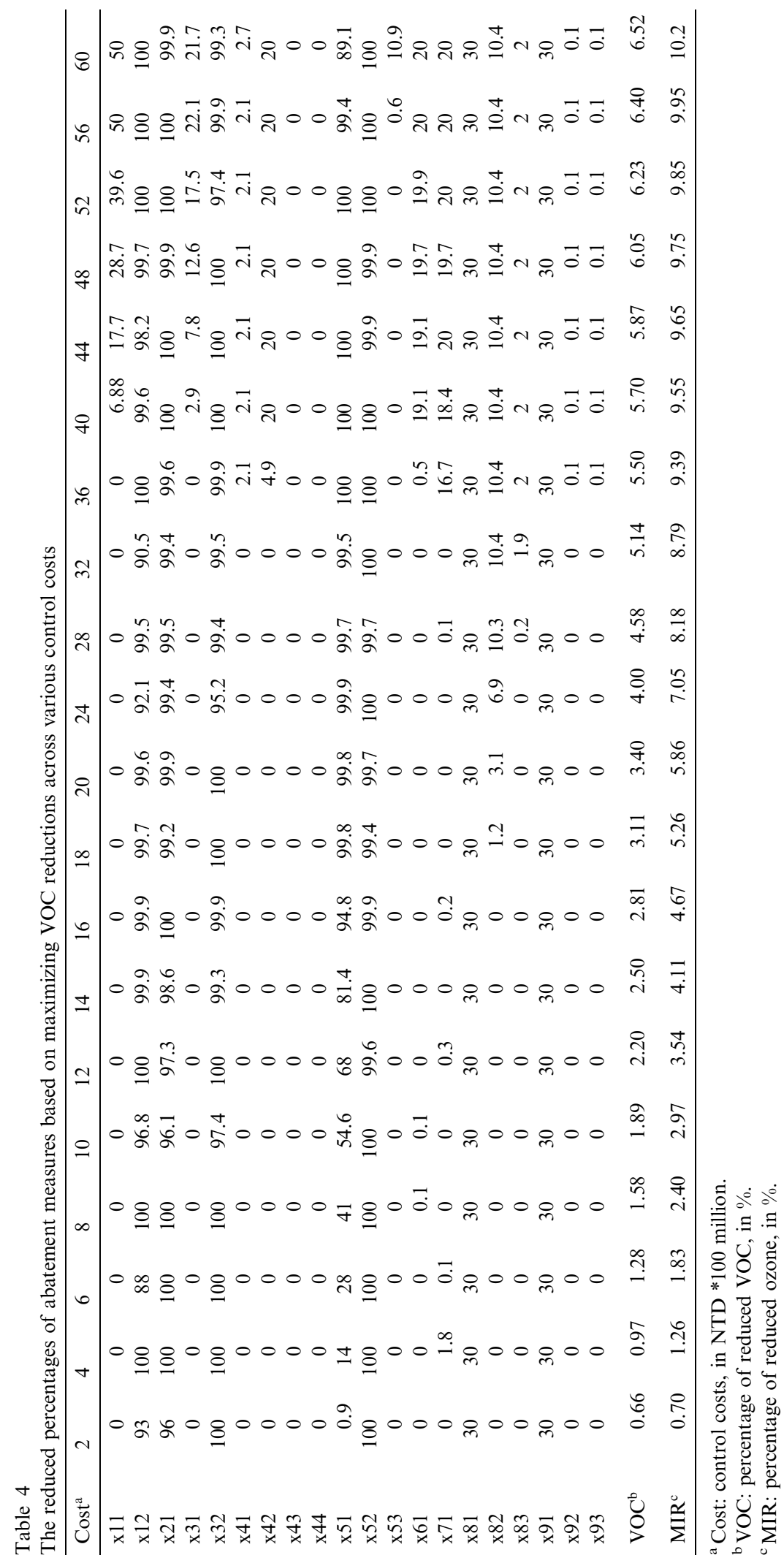




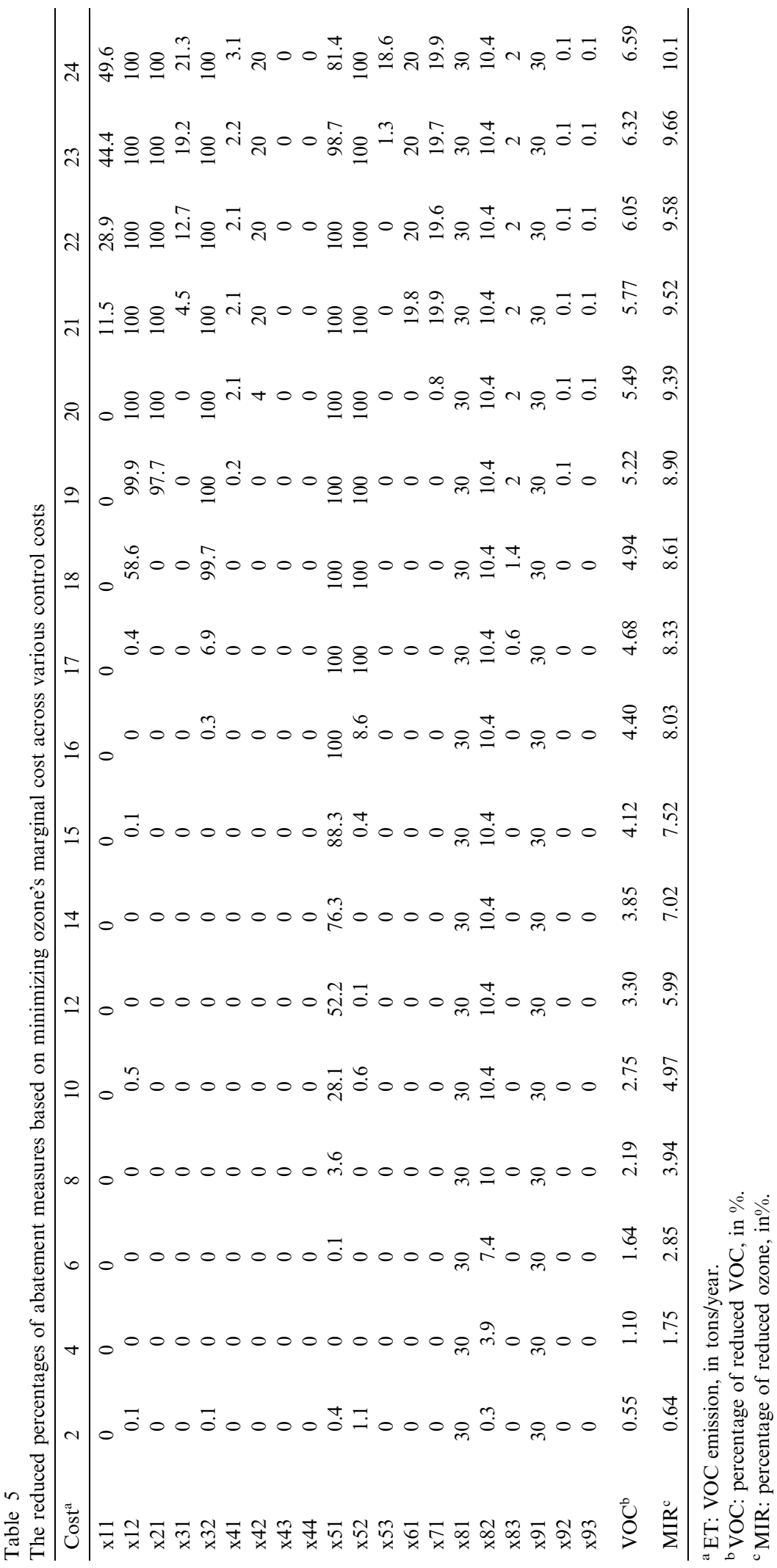


non-motorcycle I/M policies in terms of the marginal cost for minimum ozone.

5. While the control costs were higher than 2.8 billion NTD per year, the reduced percentages of abated strategies for maximizing VOC reductions and minimizing ozone's marginal cost were almost the same.

Figs. 1 and 2 describe the marginal costs for ozone and VOC across different levels of control costs. Optimization abatement for different schemes were scaled according to ozone based reactivity. The curve of minimum ozone's marginal cost fits the MIR based

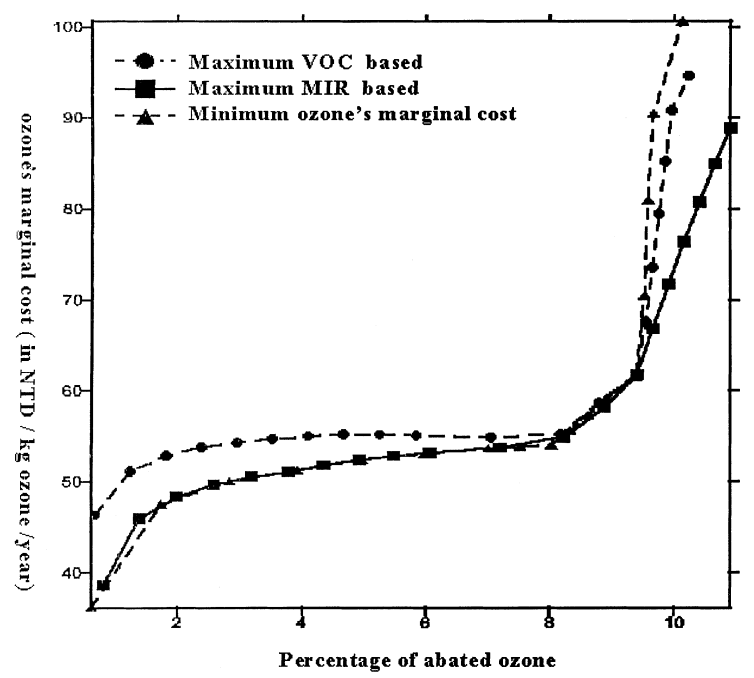

Fig. 1. Ozone's marginal cost for different objectives with varied control costs.

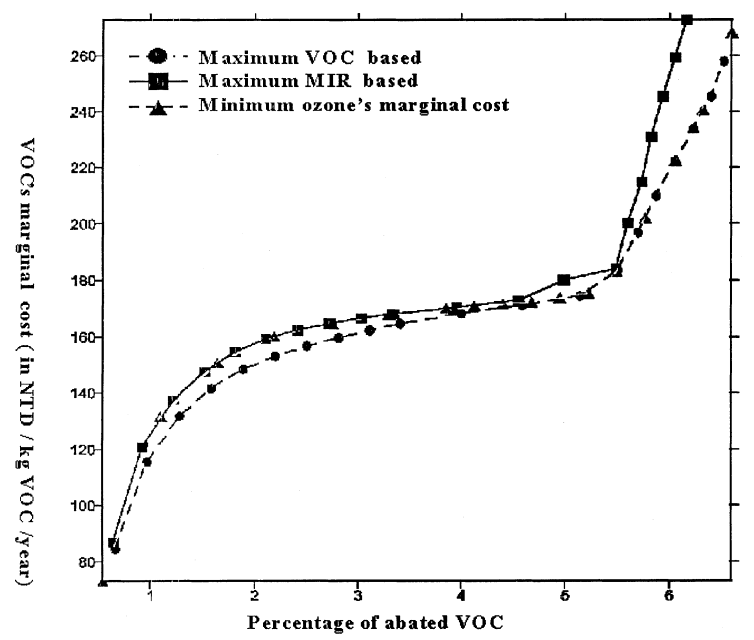

Fig. 2. VOC's marginal cost for different objectives with varied control costs. system when the ozone's marginal cost is lower than NTD 55, whereas the curve of minimum ozone's marginal cost peaks when the marginal cost is higher than NTD 55. The ozone reduction achieved with the MIR based scheme is about $7.7 \%$ and the VOC based scheme is about $2.7 \%$ when the marginal cost is NTD 54 . If the ozone's marginal cost is set as NTD 55, it could reduce ozone by $8.23 \%$ and VOC by $4.55 \%$. The curve has a steeper slope when the ozone's marginal cost is higher than NTD 55. The curve of the ozone's marginal cost also fits the MIR based system in Fig. 2 before the VOC's marginal cost reaches NTD 170; while the curve becomes similar to the VOC based one when the marginal cost is greater than NTD 170.

\section{Summary}

MC2, LDGV and MC4 vehicle types are the three greatest contributors to mobile sources with weights about $33-35 \%, 32-34 \%$ and $11-12 \%$ of mobile source based on VOC and MIR emission ratios. Taxis and MC2 vehicles were the first two vehicles to proceed with abatement measures in terms of ozone and VOC. M85 motorcycles and LPG taxis have higher proceeding priorities than the I/M policies for HDDT, buses, touring buses and taxis in the MIR based system. Nevertheless, the VOC based scheme develops the opposite solution as M85 motorcycles and LPG taxies had higher performing priorities than other non-motorcycle I/M policies.

The marginal cost analysis revealed that the curve of minimum ozone's marginal cost fit the MIR based curve in the lower marginal cost and fit the VOC based one in the higher marginal cost. Uncertainties in emission compositions, EF and control costs were the dominant factors that could effect the optimum solutions. VOC is one of ozone precursors, maximizing MIR reductions or minimizing ozone's marginal cost cannot ensure better air quality because of the complexity of photochemical reactions. More reliable, statistically significant data are needed for further investigation while the better uses of airshed or trajectory models are needed to assess ozone decline for different combinations of abatement strategies.

\section{References}

California Air Resources Board, 1991. Technical Support Document Proposed reactivity adjustment factors for transitional low-emission vehicles, Mobile Source Division, Research Division, 27.

Carter, W.P.L., 1994. Development of ozone reactivity scales for volatile organic compounds. J. Air Waste Manage. Assoc. 44, 881-899. 
Chang, L.F.W., 1997. Analyze the ozone problems in Taiwan, in: Proceedings of the 14th Conference on Air Pollution Control, Taichung, Taiwan, pp. 579-586.

Chang, Y.Y., Rudy, S.J., 1990. Ozone-formation potential of organic emissions from alternative-fueled vehicles. Atmos. Environ. 24a, 2421-2430.

Haith, D.A., 1982. Environmental Systems Optimization. Wiley, New York.

Kuo, D.C., 1988. The Principles and Theories of Sampling. Wu-Nan Book.

Lucher, D.R., Jackson, M.D., Walsh, M.P., Hsu, C.C.F., 1992. The role of alternative fuels in reducing emissions from mobile sources in Taiwan, ROC. Alternatives Fuels in Transportation, Society of Automotive Engineers.

Mcnair, L.A., Russell, A.G., Odman, M.T., 1994. Airshed model evaluation of reactivity adjustment factors calculated with the maximum incremental reactivity scale for transitional-low emission vehicles. J. Air Waste Manage. Assoc. 44, 900-907.
National Research Council, 1991. Rethinking the Ozone Problem in Urban and Regional Air Pollution. National Academy Press, Washington, DC.

Russell, A.G., Milford, J., Bergin, M.S., Mcbride, S., Mcnair, L., Yang, Y., Stockwell, W.R., Cores, B., 1995. Urban ozone control and atmospheric reactivity of organic gases. Science 269, 491-495.

Taiwan EPA, 1996. Update and setup the emission factors models and driven pattern for the mobile sources in metroTaipei.

Taiwan EPA, 1997. Research on prevention and control strategies for ozone pollution, EPA-86-FA42-09-02.

US Environmental Protection Agency, 1993. Volatile organic compound, particulate matter, speciation data system user's menu version 1.5, Office of Air Quality Planning and Standards, Research Triangle Park, NC.

US Environmental Protection Agency, 1996. User's guide to MOBILE5B, Office of Air and Radiation, Office of Mobile Sources, NC. 